\title{
WEALTH, VOLUME AND STOCK MARKET VOLATILITY: Case of Hong Kong (1993-2001)*
}

\author{
Matthew C. $\mathrm{Li}^{\dagger}$ \\ Department of Economics, Trinity College Dublin \\ Ireland
}

\begin{abstract}
This paper attempts to answer the question of whether the gain and loss in property market speculations and rate of information flow play a significant role in stock market volatility in Hong Kong. To test for our wealth-volume-volatility hypothesis, two different measures of volatility: Absolute (absolute value of standard deviation from mean with monthly dimension) and conditional $(\mathrm{EGARCH})$ are used and results are compared. In both measures we find evidence of a positive wealth effect on stock market volatility, in particular in the investment of upper luxury class of property in Hong Kong. To account for this result, we apply the newly developed conditional confidence theory. Although we fail to establish a volume-volatility relationship in our estimation, we offer additional dimensions to the explanation of our observation.
\end{abstract}

JEL Classification: C22, D14, G14, G15.

Keywords: St ock market volatility, wealth effect, conditional confidence, trading volume.

\footnotetext{
* I would like to thank Andrew Somerville for very valuable comments. I am in debt to Mike Harrison for technical advice and suggestions. I also gratefully acknowledge the support of a TCD Ussher Fellowship Award. All errors and omissions remain the responsibility of the author. Any opinions expressed are those of the author and not those of the Department of Economics, Trinity College Dublin.

${ }^{\dagger}$ Address of Correspondence: Department of Economics, Trinity College Dublin, Dublin 2, Ireland. Email: mcli@tcd.ie. Tel: 353-1-6081041.Fax: 353-1-6772503.
} 


\section{$1 \quad$ Introduction}

The majority of studies of market volatility focus on two areas: how trading volume affects movements of stock prices [Karpoff (1986, 1987), Jones et al (1994), Xu and Wu (1999)], and alternatively how human behaviour plays an influencing role in investment decision making [Barberis, Huang and Santos (1999), Robert Shiller (1998, 2000), Rabin (2000), Odean $(1998,1999)]$. This paper attempts to incorporate both areas into our investigation. Firstly, we examine how human behaviour such as a change in wealth affects people's investment decision in the stock market and secondly through the study of trading volume, we analyse whether it adds extra movements to stock prices.

To the best of our knowledge, the most distinctive feature of this paper lies in the fact that we are the first to test the hypothesis that the property market bubble, that started after the 1987 crash in Hong Kong, generated a wealth effect which changed the degree of loss aversion of investors in such a way that stock market volatility increased. We aim to answer the question, whether the gain and loss in property speculations and rate of information dispersion possess the power to explain market volatility in Hong Kong. To achieve that, we seek to examine the relationship between wealth, trading volume and stock market volatility. We are interested in this topic partly because there has been limited work done directly on linking these two topics to market volatility. More importantly, the observed trend in abnormal trading and wealth, which we assume mostly originated from property speculations, raises interesting questions in terms of investor behaviour.

The organization of this paper is as follows: In Section 2, we present some background information on the Hong Kong situation, which forms the basis of our inquiry. Section 3 reviews the prospect theory, the house money effect and the theory of overconfidence and it discuses how they each contributes to our construction of the conditional confidence theory. Section 4 specifies the development of the models under investigation and the data used. Estimation results are presented in Section 5. In Section 6, some concluding remarks with policy implications from our findings are offered.

\section{The Hong Kong Case}

Before we proceed with our study of stock market volatility, we present evidence to support evidence to our choice of country amongst the three major stock markets of recent times, 
Hong Kong, Japan and the United States. Daily trading figures from the Hong Kong Hang Seng Index (HSI), Japan Nikkei 225 Index (Nikkei) and the U.S. Standard and Poors' 500 Composite Index (SPC) are examined.

In Tables 1 and 2, numbers of days with more than 5 percent change (increase and decrease) in these three indices are shown. Considering both the number of days and the magnitude of these changes, Hong Kong leads in both categories, followed by Japan and then the U.S. On $28^{\text {th }}$ October 1997 immediately after the onset of the Asian Financial Crisis $(A F C)$, Hong Kong experienced the largest one-day drop of 13.71 percent in stock prices; this was followed by an 18.82 percent increase on the following day. From these two tables, it maybe seen that the HSI moved by more than five percent on nearly twice as many days as the other two indices combined. Therefore, we are confident in asserting that volatility in the Hong Kong stock market is substantially higher than in Japan and the U.S. Another interesting pattern that emerges from these figures is that of reversals: large drops in stock prices followed immediately by large increases. Between $4^{\text {th }}$ January 1988 and $29^{\text {th }}$ December 2000, in Hong Kong there existed eight occasions of reversal. In addition to the $29^{\text {th }}$ October 1997 reversal, consider the example of $22^{\text {nd }}$ May 1989 when there was a one-day drop of 10.78 percent but the following day there was a reversal of a 9.3 percent gain. Looking at the numbers in both tables, we can only identify two reversals for the Nikkei and one for the SPC. These reversal patterns certainly show that an increase in stock market volatility brings an increased chance of large stock price changes of either sign. In line with this reversalvolatility relationship, the Hong Kong case of greater volatility also comes with more occasions of price reversals and this validates our choice of country for stock market volatility study.

The next piece of evidence of a volatile Hong Kong stock market comes from the visual examination of Figure 1. Figure 1 depicts the monthly volatility of daily returns based on the HSI, Nikkei and SPC indices for the $4^{\text {th }}$ January 1988 to $29^{\text {th }}$ December $2000 .{ }^{1}$ Once again, these three graphs confirm that the HSI exhibits a much greater volatility than the other two indices. In Japan, there are ten occasions when the volatility level is higher than the 10 percent level with the highest achieved at 15.19 percent in October 1990. The U.S. market has only one occasion in which it came close to the 10 percent level: in October 1987, with a volatility level of 9.67 percent. The Hong Kong market tells a completely different story: there are seventeen cases when volatility rose above the 10 percentage point with the highest

\footnotetext{
${ }^{1}$ These three markets' stock volatility is measured by equation (5) of this paper.
} 
of 26.47 percent occurring also in June 1989 and subsequently a similar peak of 28.24 percent following the outbreak of the $A F C$ in October 1997. Once again, based on these observations, one can see that the Hong Kong stock market during the past fourteen years has definitely been more volatile than the other two major international stock markets. For that reason, Hong Kong provides an interesting location to study the relationship between wealth, trading volume and stock market volatility.

\section{Wealth, Confidence and Risk}

To illustrate our hypothesis of a wealth effect on stock market volatility, a model built on the prospect theory, house money effect and overconfidence which we shall call the conditional confidence theory will be developed and used.

\subsection{Prospect theory}

The prospect theory of Kahneman and Tversky (1979) is a psychology-based behavioural theory emphasizing 'loss aversion'. The loss aversion feature states that people are much more sensitive to reductions in wealth than to increases. In general, prospect theory maximizes a weighted sum of utilities that are determined by a value function. These weights reflect the degree of certainty of events. The value function has a kink at a point - 'reference point', which is the individual's point of 'status quo'. The two main features of this theoryweighted sum of utilities and the value function of prospect theory - fit in well with our hypothesis of wealth and stock market volatility. Firstly, underpinning this theory is the maximization of a weighted sum of utilities, which are based on the probabilities of events. It is reasonable to assume that those stock market investors in Hong Kong who have been previously successful in activities in the property market would tend to assign a heavy weight to the event of speculative success in the stock market. Consequently they would be more willing to take on additional risks. Secondly, the value function, which is based on the reference point - 'status quo' - plays a crucial part in investment decision making. Applying the prospect theory to the Hong Kong case, we believe that given an existing higher wealth level, once again assuming it resulted from property market success, this would move the point of status quo to a higher level. As a result, people's loss aversion would be reduced. We can summarize the dynamics of the theory as follows: 


$$
W T A R_{t}=a\left(W L T_{t}\right)
$$

where WTAR is the willingness to take additional risk and WLT stands for wealth. Equation (1) says that as current period wealth increases, willingness to take on additional risk in the current period increases by the amount of the coefficient $a$. As we shall see later on, this statement plays an essential part in the subsequent development of our conditional confidence theory.

\subsection{House money effect}

Thaler and Johnson (1990) propose the 'house money effect' to account for why some individuals are less risk averse than others. According to this theory, a loss is less painful after a substantial prior increase in wealth. As a result, these people are less risk averse and take on bets with higher risk. The house money effect reflects the situation in which gamblers are more willing to take on bets when ahead. Using the notations presented above, we can sum up the dynamics of this theory by a positive relationship between current period willingness to take on additional risk and wealth of pervious period. This relationship is depicted by the following equation:

$$
W T A R_{t}=b\left(W L T_{t-1}\right)
$$

Once again, applying the house money effect to the investment state of affairs, the rationale follows that the degree of pain or loss is not constant over time and it depends on prior investment performance. In effect, people are more sensitive to a loss following another loss whereas a loss after a substantial gain is a lot less painful. This effect is acutely appropriate in supporting our proposition of how a once successful property market investor becomes a risk lover and a noise trader in the Hong Kong stock market. With additional wealth $\left(W L T_{t-1}\right)$, losing part of the money in the stock market becomes a trivial outcome since the pain of a

loss is comfortably cushioned by prior gains thus risk aversion decreases $\left(\uparrow W T A R_{t}\right)$.

\subsection{Overconfidence}

Overconfidence is another pertinent idea behind our proposition of a relationship between wealth and stock market volatility. Overconfidence can be seen as an individual's excess 
confidence about his/her own judgement. This shapes the centre and the driving force of the network interlinking the other two theories discussed above. Without this extra confidence, our hypothesis of the wealth effect would be greatly weakened. In Odean $(1998,1999)$ and Shiller (1998), overconfidence is considered as a general human trait with little reference to the source of such behaviour. In this paper, we attach an important source to the origin of investor's overconfidence and we shall call it the conditional confidence theory. The relationship between the overconfidence theory and investors' risk taking attitude can be showed as:

$$
W T A R_{t}=c\left(O C_{t}\right)
$$

Once again, a person's willingness to take additional risk during the current period has a positive relationship with the current period overconfidence and will be increased by amount of $c$ when overconfidence increases.

\subsection{Conditional confidence theory}

Combining prospect theory, the house money effect and the overconfidence theory we have the conditional confidence theory as shown in equation (4).

$$
W T A R_{t}=f\left(W L T_{t}, W L T_{t-1}, O C_{t}\right)
$$

It is our belief that the conditional confidence theory which is built on incorporating the three theories together further reinforces the explanation of why people can be economically and financially irrational when it comes to risk taking. In general, but specifically in application to the case of Hong Kong, we believe that investors' overconfidence is conditioned on both their human instinct and also their prior experience or prior wealth and current wealth situation. With these two wealth aspects working concurrently, it produces excess assessment of investors' abilities to beat the stock market thus driving them to become less rational and fall into the category of noise traders. Table 3 presents the working of this hypothesis and shows how the chain of events starts from a simple change in property price and eventually, through the essential feature of changing confidence, leads to extra volatility in the stock market. 
In this paper as the title indicates our interest of empirical testing is in wealth effect. There exists very minor difference between the conditional confidence theory and the wealth effect. Since our model specification only includes the current and past wealth variables with the functioning of overconfidence implicitly assumed in the model, to avoid confusion we call it the wealth effect. Nevertheless, the conditional confidence theory that is developed in this paper offers us a very useful tool to theoretically account for the behaviour of some the Hong Kong investors during the time period being studied.

\section{$4 \quad$ Model Specification and Data Description}

We begin our testing of the relationship between stock market volatility, wealth effect, abnormal trading volume and volatility persistence by describing the theoretical expected contribution of individual variables in our formal model and the way each is measured.

\subsection{Stock market volatility}

In this paper, monthly stock market volatility is computed by using two different volatility models: absolute volatility and conditional volatility.

\subsubsection{Absolute volatility}

In the absolute volatility model, we shall make use of the following equation: ${ }^{2}$

$$
\hat{\sigma}_{m}=\left[\sum_{i=1}^{N_{T}}\left(r_{i, m}-\mu_{m}\right)^{2}\right]^{\frac{1}{2}}
$$

where $r_{i, m}$ is the log daily returns on the stock market index in month $m$, there are $N_{T}$ number of trading days within the month $m$, and $\mu_{m}$ is the monthly log daily mean return. Unlike the conventional standard deviation measure, although we use the sum of daily deviations from mean to calculate $\hat{\sigma}_{m}$ it has the monthly dimension because we do not divide it by the square

\footnotetext{
${ }^{2}$ The general formulation of volatility measure is developed in Schwert (1990b), howe ver we take the absolute value of this measure as a modification.
} 
root of the number of trading days. Finally, $\left|\hat{\sigma}_{m}\right|$ the absolute value of $\hat{\sigma}_{m}$ in percentage terms is the required estimate for monthly absolute stock market volatility, henceforth in this paper called $V O L_{t}$. This stock market volatility forms the basis of our studies and serves as the endogenous variable in our first estimation model.

\subsubsection{Conditional volatility (EGARCH)}

There is overwhelming evidence of the time-varying conditional variance (volatility) of asset returns (Bollerslev, Chou and Kroner (1992)). The Autoregressive Conditional Heteroscedastic (ARCH) model introduced by Engle (1982) is a frequently used volatility measure that takes into account the possibility of such a phenomenon in financial time series. The differences in the various types of $\mathrm{ARCH}$ models stem from how the conditional variance evolves over time. In the basic ARCH (1) model, conditional variance at time $t$ is a function of the squares of past shocks $\left(h_{t}=\varpi+\alpha \varepsilon_{t-1}^{2}\right)$. A generalized ARCH $(\operatorname{GARCH}(1,1))$ model $\left(h_{t}=\bar{\varpi}+\alpha \varepsilon_{t-1}^{2}+\beta h_{t-1}\right)$ specifies that the conditional variance $h$ is a function of an intercept $(\varpi)$, a shock ${ }^{3}$ from the prior period $\left(\varepsilon_{t-1}\right)$ and the variance from last period $\left(h_{t-1}\right)$.

In these two types of $\mathrm{ARCH}$ models there is the assumption that conditional volatility of the asset is affected symmetrically by positive and negative shocks - the square of the lagged shock term. For stock returns it is particularly unlikely that positive and negative shocks have the same impact on the volatility. In fact, according to So, Li and Lam (2002), by using a threshold stochastic volatility model which lets the parameters switch between the two regimes corresponding to the rise and the drop of asset prices, they find strong evidence of asymmetries in the mean and variance of the SPC and HSI data plus better forecast power for future conditional variance. We are not entirely surprised to see asymmetries present in return data. According to the leverage effect theory, as the price of a stock falls, its debt-toequity ratio rises, thus increasing the volatility of stock returns to the stockowners. Furthermore, we do observe in the real world the situation of panic selling upon arrival of a piece of bad news to a company, while in comparison panic or rush buying of stocks due to good news is less frequent and pronounced. In other words, the variance will be higher under bad news or a price fall than under good news or price rise.

\footnotetext{
${ }^{3}$ Frequently, this shock is also referred as 'news', or 'error', or 'unpredictable component' of a time series.
} 
Considering the potential existence of asymmetry in stock returns and the desire to investigate the leverage effect in the HSI data and test for forecast power of our models, we chose the EGARCH (Exponential GARCH) $(1,1)$ model to generate the conditional stock market volatility that we require in the second model. The specification of the EGARCH conditional variance is as follows:

$$
\log \left(h_{t}\right)=\bar{\omega}+\alpha\left|\frac{\varepsilon_{t-1}}{\sqrt{h_{t-1}}}\right|+\beta \log \left(h_{t-1}\right)+\gamma \frac{\varepsilon_{t-1}}{\sqrt{h_{t-1}}},
$$

The left hand side is the log of the conditional variance. This implies that the leverage effect is exponential rather than quadratic, and that forecasts of the conditional variance are guaranteed to be nonnegative. The presence of the leverage effect can be tested by the significance of $\gamma$ and the hypothesis that it is smaller than zero. The impact is asymmetric if $\gamma \neq 0$. Furthermore, when the shock coefficient and the coefficient of last period conditional variance sum up to $1(\alpha+\beta=1)$, it means that there is a unit root in the conditional variance; viz. past shocks do not dissipate but persist for a very long period of time.

\subsection{Wealth effect}

To estimate the wealth effect, we use different classes of the private domestic monthly property price index $P R T$. We take the absolute value of the monthly property price return as our required change in wealth measurement. In its simplest form, property market returns $R E T(k)_{t}$ at time $t$ for each individual class are calculated as:

$$
R E T(k)_{t}=\left|\log \left(\frac{P R T_{t}}{P R T_{t-1}}\right) \times 100\right|,
$$

where $k$ signifies various property classes. There are eight different classes of private domestic property according to saleable area. 


\subsection{Abnormal trading volume}

For trading volume, we use the measure of abnormal volume. According to Karpoff (1986), there exists persistence ${ }^{4}$ in the amount of trading volume. ${ }^{5}$ After running regressions on 12 lags of monthly volume growth rates (TVOLM) in percentage, we found that persistence only exists in the first lag. Thus the absolute value of the residuals $\left|\hat{e}_{t}\right|$ obtained from the following equation give us the amount of abnormal trading volume (ATV):

$$
\operatorname{TVOLM}_{t}=\lambda_{0}+\lambda_{1} \operatorname{TVOLM}_{t-1}+e_{t}
$$

\subsection{Volatility persistence}

Recent literature on stock market volatility (Xu and Wu (1999), Jones et al. (1994) and Schwert $(1989,1990 \mathrm{a}))$ has paid notable attention to the persistence of volatility. Continuing with the convention and also attempting to test for presence of volatility persistence in our model, three lags of stock market volatility are included.

\subsection{The core models}

To gauge the characteristics of the volatility-wealth-volume relationship, two core models are set up according to the way stock market volatility is measured.

Absolute volatility model:

$$
V O L_{t}=\theta_{1}+\theta_{2} R E T(k)_{t}+\theta_{3} R E T(k)_{t-1}+\theta_{4} A T V_{t}+\theta_{5} V O L_{t-1}+\theta_{6} V O L_{t-2}+\theta_{7} V O L_{t-3}+u_{t}
$$

\section{Conditional volatility (EGARCH) model:}

$$
\log \left(h_{t}\right)=\varpi+\alpha\left|\frac{\varepsilon_{t-1}}{\sqrt{h_{t-1}}}\right|+\beta \log \left(h_{t-1}\right)+\gamma \frac{\varepsilon_{t-1}}{\sqrt{h_{t-1}}}+\phi_{1} R E T(k)_{t}+\phi_{2} R E T(k)_{t-1}+\phi_{3} A T V_{t}
$$

\footnotetext{
${ }_{5}^{4}$ Persistence result from frictions in the clearing process such as computer clearing delays.

${ }^{5}$ In millions of Hong Kong dollars.
} 
Equation (10) infers that in addition to information contained in the stock price index series' history, there exist other factors of the market around them that also contribute to the volatility of the returns.

Although both absolute volatility and conditional volatility models are used to test the volatility-wealth-volume relationship, there is one key difference between them. In the first model, we run OLS on equation (9) to try to establish a statistical relationship between individual exogenous variables. However, in (10) we include three exogenous variables (current and past change in wealth and abnormal trading volume) and attempt to test for their contribution in the process of generating the conditional variance by following an EGARCH method.

\subsection{Data Description}

All data used in this paper are monthly data covering the sample period of February 1993 to July 2001. Hong Kong stock price index - HSI data together with stock trading volume measured as turnover in Hong Kong dollars - are used.

Monthly property price data that are collected from the Private Domestic - Price Indices by Class (Territory-Wide), which is published by the Rating \& Valuation Department, Hong Kong Government are categorised as follows:

\begin{tabular}{c|l}
\multicolumn{2}{c}{ Categorization of property classes $^{\mathbf{6}}$} \\
\hline \hline Class $A$ & Small Residential \\
Class $B$ & Medium Residential \\
Class $C$ & Large Residential \\
Class $D$ & Lower Luxury \\
Class $E$ & Upper Luxury \\
Class $A B C$ & Residential \\
Class $D E$ & Luxury \\
Class $A L L$ & Overall \\
\hline \hline
\end{tabular}

\footnotetext{
${ }^{6}$ This paper focuses on properties that are solely for residential purposes.
} 


\section{$5 \quad$ Empirical Results}

\subsection{Absolute stock market volatility model}

To identify clearly the volatility-wealth-volume relationship in our first model, we run regressions on equation (9) according to each individual property return class. Results of these estimations are presented in Table 4.

Looking at these results, a very distinctive picture appears. In all the eight models that we have tested, only when $k=C$ and $E$, and to a less extent Class $D E$ i.e. for the large residential and upper luxury classes of property return do we obtain a significant wealth coefficient of 0.703 and 0.604 respectively at 5 percent critical level, whereas for all other property class return coefficients we fail to reject the null hypothesis that they are equal to zero. This implies that a 1 percent increase in wealth from speculating these two classes of property leads on average to about 0.7 to 0.6 percent increase in the stock market volatility. A coefficient of this size certainly suggests an influential relationship and provides valuable information to both policy makers and investors. Let us assume that, for some reasons that are pertinent to the operation of the economy, the government aims to reduce stock market volatility by a certain percentage, together with adjustment on other market factors such as interest rate and corporate bond return. ${ }^{7}$ This objective can be partly achieved through the stabilization of these two classes of property price. For these Class $C$ and Class $E$ models, the explanatory powers are the strongest among all property classes with an adjusted $R^{2}$ ranging from 0.374 to 0.385 together with $F$-statistics of 10.758 and 11.217 respectively, which reject the null hypothesis that all slope coefficients are simultaneously equal to zero.

The other important estimation result is the highly significant volatility persistence in the first lag. This volatility persistence consistently appears in all eight regression models with the size of the coefficient at around the 0.4 level but it decays to about half of its original value by the third lag. Nonetheless, the persistence of stock market volatility with its relatively large size of around 0.4 in the first lag reveals its key role in causing present volatility.

From the outset we seek to test for the existence of a positive relationship between market volatility and $A T V$. The estimated $A T V$ coefficients, apart from being highly insignificant at all critical levels, also carry a very small size of equal to or less than 0.005 .

\footnotetext{
${ }^{7}$ For a discussion of these potential factors see Schwert (1989).
} 
There exist numerous previous studies ${ }^{8}$ that also fail to establish such a relationship so we are not entirely disappointed or surprised by our results.

\subsection{Conditional stock market volatility (EGARCH) model}

The second approach in testing our hypothesis of a volatility-wealth-volume relationship is the use of an EGARCH model to generate conditional stock volatility. By incorporating wealth and volume as exogenous variables in the conditional variance equation of an EGARCH model, we hope to identify how these variables affect the conditional volatility generation process. Estimation results of this EGARCH model are presented in Table 5.

Our estimation results show that amongst all eight property classes, the wealth effect variable for Classes $D, E$ and $D E$ are significant in generating stock market volatility. In particular the Class $E$ property return is highly significant at 1 percent critical level. This result is in line with those we obtained from the absolute volatility model, nevertheless, these significant wealth coefficients are only half the size of those in the previous model. We are not entirely surprised by this observation because the coefficient $\phi_{1}$ in equation (10) means that a 1 percent change in property returns changes volatility by a factor of $\exp \left(\frac{\phi}{2}\right)$. By contrast, the absolute volatility regression suggests the level of volatility changes by $\theta_{2}$. So we would expect $\theta_{2}=\left(e^{\frac{\phi}{2}}-1\right) V O L \approx \frac{\phi V O L}{2}$. The estimates seem to be pretty well consistent with this. Once again we fail to detect any significant contribution of our abnormal trading variable $(A T V)$ to the conditional volatility. This is in line with our previous finding even in terms of the size of the estimated coefficients.

As mentioned earlier when $\alpha+\beta=1$, it implies that volatility persistence exists. Looking at our results, we notice that both $\alpha$ and $\beta$ are nearly all insignificant except in one occasion of Class $C$ property. In other words, volatility persistence seems to be absent in our conditional volatility model. However, in order to ensure that this model has adequately captured all of the persistence in the variance equation, we complete the Ljung-Box Qstatistic. If the model is adequate, then the standardized squared residuals should be serially uncorrelated. Ljung-Box Q-statistics at six lags of the standardized squared residuals presented in Table 4 indicate that they are indeed serially uncorrelated.

\footnotetext{
${ }^{8}$ See Karpoff (1987) for a list of previous studies that fail to find a trading volume and stock price relationship.
} 
The presence of the leverage effect can be detected through the hypothesis that $\gamma \neq 0$. Estimated results of $\gamma$ in Table 4 show that we fail to reject the hypothesis that $\gamma=0$ for all property classes. Hence, we have to conclude that maybe a fall in stock return has the same impact as a rise in returns, viz. the impact is symmetric. Although previously we mentioned that So, Li and Lam (2002) have found significant results illustrating the asymmetric impact of HSI daily data, we suspect that because we utilize a monthly measurement of volatility, much of the leverage effect has disappeared within a month's time.

\subsection{Estimation result summary}

The most interesting finding of this paper comes from our estimation results of property Class $E$, that is wealth gained from upper luxury property. Although we aim to establish a positive wealth relationship with stock market volatility for all classes of property, we only find a consistently strong wealth effect in this class. Are we surprised in finding that only wealth created from speculating in the luxury class property has a positive relationship with stock market volatility? We can examine and answer this question in various ways and they all lead to the same conclusion that the result accords with the observation and theory. Descriptive statistics of our data series in Table 6 show that this class of property return, though carrying the highest standard deviation amongst all eight property market returns, also produces the highest mean return of 1.890 percent per month. This observation tells us that if one were to speculate in the Hong Kong property market during 1993 to 2001, investing in this upper luxury property would on average deliver the best return together with the biggest monetary gain. ${ }^{9}$

The residential classes of property have the lowest returns, quite conceivably because most buyers are purchasing properties for their own housing purpose or for long-term investment. Therefore frequency of transaction and price change (return) would be lower than the luxury classes, where the higher returns attract frequent transaction activities to realize the capital gains. In this case, any gain or loss from these residential property purchases will not be quickly realized and the gains would not be channelled into the stock market, hence the wealth effect on the stock market failed to materialize. High return also comes with high risk.

\footnotetext{
${ }^{9}$ Since the amount of original investment in upper luxury property could easily be many times over that of residential class, therefore, a 2 percent return for a upper luxury property could give a substantial gain in money terms over other classes of property.
} 
The gain and loss from luxury property speculation, especially when one is engaged with a high level of leverage financing, can simply be considered as a risking behaviour.

In order to participate in speculation in upper luxury property, an investor needs a substantial amount of capital to support the initial down payment and the subsequent monthly mortgage payments. ${ }^{10}$ Furthermore, our empirical result infers the situation that the biggest players would be from the middle class and wealthy investors who traditionally were also more inclined to be regular participants, particularly in the stock market.

Besides the initial wealth that these groups of investors possessed, the easy credit situation during that time also created a vicious cycle. When applying for personal or mortgage financing, in general, the banks would take into account the borrower's professional status, income level and amount of present asset holding. Therefore, when a person has already maintained title for a few pieces of upper luxury property with rising prices, it is not difficult to envisage that the bank would take a very lenient approach in granting additional credit even if the fund was likely to be used for additional property speculation. Supplemented with more credit, more speculation activities would be supported. Following the $A F C$, when the property market began to collapse, the amount of overdue bank leverage payments was so large that many people were heavily in debt and forced to sell the property at an unreasonably low price while dumping their stock holdings in the stock market. When these two actions were taken simultaneously, this caused extra volatility in both markets and for some of the more unfortunate ones ${ }^{11}$ the ultimate result was the inevitable bankruptcy. In any case, we suspect ${ }^{12}$ that the most significant flaw in the whole 'game' came from the fact that when this speculation extravaganza started, the increase in the number of irrational speculators changed the proportion of informed (rational) traders to noise (irrational) traders thus allowing this wealth effect to arise and to persist. It is exactly this composition change, which exacerbated the extra volatility that we observe in the Hong Kong stock market data during our sample period.

Putting all the results together, we establish some essential interpretations and observations. Firstly, for wealth accumulation from investments in upper luxury property, statistically we fail to reject the hypothesis that success in property market speculations contribute significantly to stock market volatility. So how do we make use of our conditional

\footnotetext{
${ }^{10}$ We assume the event of paying up the full amount at one time being an unlikely and unreasonable event, as this will only substantially reduce the amount of capital available for additional property purchases. ${ }^{11}$ Unfortunate in terms of the huge amount of loss sustained from both property and stock markets.

${ }^{12}$ Our suspicion is partly based on empirical results of this paper which finds a wealth effect in the upper luxury class property investors and also the news coverage at that time regarding the intensity of people's preoccupation with the markets.
} 
confidence theory to account for this wealth effect of the Hong Kong case? As mentioned above, during this period, many people in Hong Kong were preoccupied with their involvements in these two markets and our estimation results support our claim that those upper luxury property investors who achieved success in the property market advanced their belief of having the ability to beat the stock market. By assigning a higher weight to a positive outcome and by changing their reference point, loss aversion of this group of investors was reduced. This phenomenon certainly fits in well with the prospect theory of Kahneman and Tversky (1979). Furthermore, and might be to a much lesser extent, the fact that these investors were successful in the upper luxury property speculation also brought substantial monetary rewards. Naturally with more money in hand, they felt less pain if ever they had to lose part of it and this is exactly what the house money effect hypothesis predicts. Carrying these two factors with them, overconfidence amongst investors developed and it was precisely this confidence per se (or extreme overconfidence) that somehow drove them into taking irrational actions, which also turned them into risk lovers and exacerbated further volatility in the stock market.

One might question that when the property market began to weaken at the end of 1997, investors' confidence should also have begun to deteriorate so that its influence on stock market volatility should have disappeared. The conditional confidence theory we have devised in this paper indeed can help to explain this occurrence. The second scenario presented in Table 3 adequately describes the situation following the outbreak of the $A F C$. It is an empirical fact that, starting at the end of 1997, property prices began to fall but stock volatility remained high. Tracing the reasoning path of scenario two, it is not difficult to see that, although we saw a large decrease in property price, our measure of wealth, which is the change in absolute value of property market return, remained high. This large decline in property price caused a negative effect on the confidence of these upper luxury property previously successful speculators and they began to sell (dump) ${ }^{13}$ their stocks in the market resulting in extra movements in stock prices. Also shown in Table 3 in the first scenario is the opposite case of when there was a large increase in property price, which depicts accurately the Hong Kong case prior to the $A F C$. By using the same logic as predicted by our conditional confidence theory, this led to the same outcome of a high volatility. These analyses certainly demonstrate that our newly developed and more refined conditional confidence theory works well in both up and down market situations. Nevertheless, we have

\footnotetext{
${ }^{13}$ Either for reasons of panic or liquidity.
} 
to point out that our empirical results of no statistically significant lagged wealth variables suggest that at least for Hong Kong our conditional confidence theory is mainly driven by the prospect theory type of reaction among investors. This means that Hong Kong investors' overconfidence was mostly fuelled by current change in wealth and past wealth level was somehow ignored in their current investment decisions.

As for our failure to find a positive relationship between trade volume and stock market volatility, we can interpret this result as an indication that information plays an inconsequential role in the Hong Kong investment community. According to the simple price-volume model, we believe that disagreement amongst investors is not necessary to exist move stock price as long as news contains new information that changes people's valuation of the stock. Once again, given the high degree of stock market participation during our sample period, and also because of the stake involved, investors watched news about the market intensely and reacted to this news almost immediately, hence the surprise element of this news is substantially reduced. Consequently, price adjustment to information is very quick or nearly instantaneous and excess trading could be negligible. Indeed, the Hong Kong case proves that although there is abnormal trading volume as a result of new information, as long as these news reaction movements are very short lived, movements in stock prices will be so rapid that the effect will be difficult to observe. ${ }^{14}$

Hong Kong being one of the most densely inhabited cities in the world, with numerous newspapers, magazines, radio and television stations reporting news each day, the rate of information flow within the community could be extremely swift. Therefore, if one takes the conventional information approach to link trading volume and price movements, Hong Kong would be one of those places where the theory is inapplicable. Empirically in this paper, we have shown that information or abnormal trading volume has little effect on the Hong Kong stock returns and based on this observation we propose two probable explanations: size and participation. First, geographically speaking, for a place that is small in size such as Hong Kong and secondly for a community with high stock market participation intensity such as the time period of this studied, the information effect on the price-volume relationship is reduced. Despite the result, one cannot completely reject the theoretical hypothesis of a price-volume relationship. This hypothesis is based on valid economic and financial foundations supported by many favourable empirical results.

\footnotetext{
${ }^{14}$ This could be particularly applicable for monthly data such as those used in this paper.
} 


\section{Conclusions}

In this paper, we find supporting evidence for our hypothesis of a positive relationship between wealth and market volatility. But why should one care for such a relationship and what are the implications? The answer to the question lies in the possible detrimental effects that a volatile stock market can produce. A stable market environment possesses many advantages for the economy. For most long-term investors, both domestic and overseas, a stable market provides assurance in their investments while a volatile market weakens investors' confidence. With short-term speculations, capital investment that is needed to support a country's infrastructure cannot be sustained. The stock market is an important place where local companies secure their capital to finance their development and operations on a long-term basis. According to the general asset-pricing model, stock prices should reflect adequately the future returns (or stream of future dividend payments) from this investment. From a broader point of view, movements of the market should reveal all the fundamentals of the economy (both current and expected). In other words, the driving force behind the movements of the market should be the economy, not the sentiments of speculators for quick

profits. However, there seems to be evidence showing that the market is quite often dictated by purely speculative activities.

Furthermore, in a market economy, price is one of the important pieces of information for policy formulation. If prices do not reflect the underlying fundamentals, misguided policies may be made in consequence. It is true that one cannot control the amount of trading in an open market. However, this paper has shown that in Hong Kong property market fluctuations have adverse effects on stock market volatility; reducing these fluctuations may be a more powerful and warranted policy for the Hong Kong government to consider.

Hong Kong for a long time has enjoyed the reputation as being one of the most laissez faire market economies in the world. Nonetheless, two events in recent years have tarnished its reputation in the international financial community. In August 1989, the Hong Kong government took the unprecedented step of supporting the stock market by purchasing total HK $\$ 118$ billion (US $\$ 15.13$ billion) worth of stocks, which was about 2.5 percent of the total market capitalization of all stocks at that time. This act shook many international observers and the question of whether Hong Kong could ever remain a completely free market economy was raised as a result. 
The second dilemma is still an ongoing issue under the current Hong Kong government agenda. Arising from the collapse of the property market in late 1997, the government has been under constant pressure to intervene and to try to support property prices, both from the property developers and those who incur huge losses in property investments. ${ }^{15}$ One can certainly understand the government's dilemma in this stance. On one hand the government wants to reduce the harmful effects of this property price collapse to the economy, ${ }^{16}$ on the other hand, the government is apprehensive about being criticised for market interference. The latter concern is an especially sensitive political issue following the return of Hong Kong to China in 1997.

During the past couple of years government policies have shown signs of property market support. Since 1998, under revised government policies, provision of public housing, auction of government land, amount of government loans to purchase public housing units, percentage of initial mortgage deposit and so on have all been reduced. These policies should have the effects of reducing residential land supply whilst encouraging more public participation in the private property market. For those who lost greatly in the property market, these policies may offer a chance of escape from their predicament, but for the economy as a whole we question whether a long-term gain exists.

This paper finds evidence to support the relationship between wealth and stock market volatility; therefore, if the Hong Kong government did attempt to bail out the speculators through government intervention, we should predict a stronger wealth effect on the stock market. Our basis for such a claim is not difficult to perceive because one's risk attitude is deeply rooted into how one conceives the consequences of one's actions. Therefore, the logic goes that if an investor believes that the rule of the game is "win I keep, lose someone else pays', then naturally this investor would become extremely risk loving.

According to our newly developed conditional confidence theory together with our empirical findings, any wealth creation through speculation would add substantial amounts of conditional confidence to the investor and advance speculation in the stock market with an extremely risk loving approach. It is not a bad government policy to support a market that is going through tough times, but granting the 'negative asset class' assistance such as the recently suggested special interest concession on their mortgage loans will have an effect similar to redistributing income from the more cautious risk averse group of investors to the

\footnotetext{
${ }^{15}$ A new class of people emerged as a result of the property market collapse and in Hong Kong they are now called the "negative asset class".

${ }^{16}$ Since 1998 the Hong Kong economy has suffered a recession and many blame the collapse of the property market as the main cause of the event.
} 
risk loving ones. Put aside the question of whether such an act is a Pareto improvement, and also the issue of social equality. Bailing out of this group of risk loving investors would only create a signal similar to promoting excessive risk taking behaviour among investors. The consequence is likely to be long-lasting and devastating to the economy and eventually everyone will suffer. It is imperative that the Hong Kong government must consider carefully any policies that could convey such a message. 


\section{References}

Barberis, Nicholas, Ming Huang and Tano Santos (1999), "Prospect Theory and Asset Prices," NBER Working Paper 7220.

Bollerslev, T., R. Y. Chou and K. F. Kroner (1992), “ARCH modelling in finance: a selective review of the theory and empirical evidence," Journal of Econometrics, 52: 1, 5-59.

Engle, R. F. (1982), “Autoregressive conditional heteroscedasticity with estimates of the variance of United Kingdom inflation," Econometrica 50: 4, 987-400.

Jones, Charles M., Gautam Kaul, and Marc L. Lipson (1994), “Transactions, Volume, and Volatility," Review of Financial Studies, 7: 4 (Winter, 1994), 631-651.

Kahneman, Daniel and Amos Tversky (1979), "Prospect Theory: An Analysis of Decision Under Risk," Econometrica, 47: 2, 263-291.

Karpoff, Jonathan M. (1986), “A Theory of Trading Volume,” Journal of Finance, 41: 5, 1069-1087.

Karpoff, Jonathan M. (1987), "The Relation Between Price Changes and Trading Volume: A Survey," Journal of Financial and Quantitative Analysis, 22: 1, 109126.

Odean, Terrance (1998), “Are Investors Reluctant to Realize Their Losses?” Journal of Finance, 53: 5, 1775-1798.

Odean, Terrance (1999), "Do Investors Trade Too Much?” American Economic Review, 89: $5,1279-1298$.

Rabin, Matthew (2000), “Risk Aversion and Expected-Utility Theory: A Calibration heorem," Econometrica, 68: 5, 1281-1292. 
Schwert, G. William (1989), "Why does stock market volatility change over time?" Journal of Finance, 44: 5, 1115-1154.

Schwert, G. William (1990a), “Stock Market Volatility,” Financial Analysis Journal, MayJune, 23-34.

Schwert, G. William (1990b), "Stock Volatility and the Crash of '87," Review of Financial Studies, 3:1, 77-102.

Shiller, Robert J. (1998), "Human Behavior and the Efficiency of the Financial System," NBER Working Paper 6375.

Shiller, Robert J. (2000), Irrational Exuberance, Princeton University Press.

So, Mike K. P., W. K. Li and K. Lam (2002), “A Threshold Stochastic Volatility Model," Forthcoming in Journal of Forecasting .

Thaler, Richard H. and Eric J. Johnson (1990), "Gambling with the House Money and Trying to Break Even: The Effects of Prior Outcomes on Risky Choice," Management Science 36, 643-660.

$\mathrm{Xu}$, Xiaoqing Eleanor and Chunchi Wu (1999), "The intraday relation between return volatility, transactions and volume," International Review of Economics and Finance, 8, 375-397. 
Table 1

Numbers of Days with more than $5 \%$ daily percentage INCREASE

4 January 1988 - 29 December 2000

\begin{tabular}{|c|c|c|c|c|c|c|}
\hline Rank & Date & HSI & Date & Nikkei & Date & SPC \\
\hline 1 & 29 Oct 1997 & $18.82 \%$ & 2 Oct 1990 & $13.24 \%$ & 28 Oct 1997 & $5.11 \%$ \\
\hline 2 & 2 Feb 1998 & $14.33 \%$ & 17 Nov 1997 & $7.96 \%$ & 8 Sep 1998 & $5.09 \%$ \\
\hline 3 & 23 Мау 1989 & $9.30 \%$ & 31 Jan 1994 & $7.84 \%$ & & \\
\hline 4 & 16 Oct 1998 & $8.99 \%$ & 10 Apr 1992 & $7.55 \%$ & & \\
\hline 5 & 14 Aug 1998 & $8.47 \%$ & 7 Jul 1995 & $6.27 \%$ & & \\
\hline 6 & 7 Sep 1998 & $7.86 \%$ & 21 Aug 1992 & $6.22 \%$ & & \\
\hline 7 & 12 Jun 1989 & $7.56 \%$ & 7 Oct 1998 & $6.17 \%$ & & \\
\hline 8 & 13 Jan 1998 & $7.38 \%$ & 27 Aug 1992 & $6.13 \%$ & & \\
\hline 9 & 9 Oct 1998 & $7.14 \%$ & 16 Jan 1998 & $6.11 \%$ & & \\
\hline 10 & 3 Sep 1997 & $7.13 \%$ & 6 Jan 1988 & $5.63 \%$ & & \\
\hline 11 & 24 Oct 1997 & $6.89 \%$ & 15 Aug 1990 & $5.40 \%$ & & \\
\hline 12 & 18 Jun 1998 & $6.39 \%$ & 7 Sep 1998 & $5.32 \%$ & & \\
\hline 13 & 17 Jun 1998 & $6.35 \%$ & 12 Oct 1998 & $5.24 \%$ & & \\
\hline 14 & 3 Nov 1997 & $5.94 \%$ & 8 Mar 1993 & $5.17 \%$ & & \\
\hline 15 & 14 Jan 1994 & $5.87 \%$ & 5 Mar 1999 & $5.01 \%$ & & \\
\hline 16 & 4 Dec 1992 & $5.82 \%$ & & & & \\
\hline 17 & 14 Jan 1998 & $5.81 \%$ & & & & \\
\hline 18 & 14 Apr 1993 & $5.79 \%$ & & & & \\
\hline 19 & 19 Aug 1998 & $5.71 \%$ & & & & \\
\hline 20 & 12 Oct 1998 & $5.68 \%$ & & & & \\
\hline 21 & 19 Jan 1998 & $5.62 \%$ & & & & \\
\hline 22 & 6 Feb 1995 & $5.60 \%$ & & & & \\
\hline 23 & 25 Sep 2000 & $5.58 \%$ & & & & \\
\hline 24 & 28 Aug 1990 & $5.51 \%$ & & & & \\
\hline 25 & 31 May 2000 & $5.17 \%$ & & & & \\
\hline 26 & 5 Jan 1988 & $5.11 \%$ & & & & \\
\hline 27 & 23 Mar 1994 & $5.03 \%$ & & & & \\
\hline
\end{tabular}

Note. Daily price indices from Datastream. Calculations mine. 
Table 2

Numbers of Days with more than 5\% daily percentage DECREASE

4 January $1988-29$ December 2000

\begin{tabular}{crrrrrr}
\hline \hline Rank & \multicolumn{1}{c}{ Date } & \multicolumn{1}{c}{ HSI } & \multicolumn{1}{c}{ Date } & Nikkei & \multicolumn{1}{c}{ Date } & \multicolumn{1}{c}{ SPC } \\
\hline 1 & 5 Jun 1989 & $-21.75 \%$ & 18 Apr 2000 & $-6.98 \%$ & 27 Oct 1997 & $-6.87 \%$ \\
2 & 28 Oct 1997 & $-13.71 \%$ & 2 Apr 1990 & $-6.60 \%$ & 31 Aug 1998 & $-6.80 \%$ \\
3 & 22 May 1989 & $-10.78 \%$ & 19 Aug 1991 & $-5.91 \%$ & 8 Jan 1988 & $-6.77 \%$ \\
4 & 23 Oct 1997 & $-10.41 \%$ & 23 Aug 1990 & $-5.84 \%$ & 13 Oct 1989 & $-6.12 \%$ \\
5 & 12 Jan 1998 & $-8.70 \%$ & 8 Oct 1998 & $-5.78 \%$ & 14 Apr 2000 & $-5.83 \%$ \\
6 & 17 Apr 2000 & $-8.55 \%$ & 23 Jan 1995 & $-5.60 \%$ & & \\
7 & 25 May 1989 & $-8.51 \%$ & 19 Nov 1997 & $-5.29 \%$ & & \\
8 & 19 Aug 1991 & $-8.38 \%$ & 19 Dec 1997 & $-5.24 \%$ & & \\
9 & 3 Dec 1992 & $-8.01 \%$ & 25 Nov 1997 & $-5.11 \%$ & & \\
10 & 6 Aug 1990 & $-7.42 \%$ & 11 Sep 1998 & $-5.11 \%$ & & \\
11 & 11 Mar 1996 & $-7.31 \%$ & & & & \\
12 & 5 Jan 2000 & $-7.18 \%$ & & & & \\
13 & 31 Aug 1998 & $-7.08 \%$ & & & & \\
14 & 15 Jan 1998 & $-7.02 \%$ & & & & \\
15 & 6 Jan 1994 & $-6.52 \%$ & & & \\
16 & 16 Oct 1989 & $-6.49 \%$ & & & & \\
17 & 22 Oct 1997 & $-6.17 \%$ & & & & \\
18 & 7 Feb 1994 & $-6.11 \%$ & & & \\
19 & 7 Jan 1998 & $-5.89 \%$ & & & & \\
20 & 27 Oct 1997 & $-5.80 \%$ & & & & \\
21 & 15 Jun 1998 & $-5.72 \%$ & & & & \\
22 & 11 Dec 1997 & $-5.46 \%$ & & & & \\
23 & 1 Dec 1992 & $-5.32 \%$ & & & & \\
24 & 27 May 1998 & $-5.26 \%$ & & & & \\
25 & 15 Mar 1993 & $-5.12 \%$ & & & & \\
26 & 21 Mar 1994 & $-5.10 \%$ & & & & \\
27 & 1 Sep 1997 & $-5.02 \%$ & & & & \\
28 & 13 Jan 1994 & $-5.01 \%$ & & & & \\
\hline
\end{tabular}

Note. Daily price indices from Datastream. Calculations mine. 
Table 3

Conditional confidence theory

\begin{tabular}{|c|c|cc|c|}
\hline \hline Property price $\Delta$ & $\begin{array}{c}\text { property market return| } \\
(\mid \text { wealth } \Delta \mid)\end{array}$ & Confidence $\Delta$ & Stocks & $\begin{array}{c}\text { Stock price } \Delta \text { - } \\
\text { volatility }\end{array}$ \\
\hline \hline Large $\uparrow$ & High & +ve & Buy & $\uparrow$ \\
\hline Large $\downarrow$ & High & No & Sell & $\uparrow$ \\
\hline Small & Low & No & - & - \\
\hline No & No & \multicolumn{2}{c}{} \\
\hline \hline
\end{tabular}


Table 4 Absolute Volatility

Regression results for various property market returns -- Whole Sample

Dependent Variable: $V O L_{t}$

1993:02 to 2001:07

\begin{tabular}{|c|c|c|c|c|c|c|c|c|}
\hline & $(k)=A$ & $(k)=B$ & $(k)=C$ & $(k)=D$ & $(k)=E$ & $\begin{array}{l}(k)= \\
A B C\end{array}$ & $(k)=D E$ & $(k)=A L L$ \\
\hline \multirow[t]{2}{*}{ Intercept } & $1.881 * * *$ & $1.932 * * *$ & $1.619 * *$ & $1.957 * * *$ & $1.713 * * *$ & $1.901 * * *$ & $1.874 * * *$ & $1.887 * * *$ \\
\hline & $(0.661)$ & $(0.695)$ & $(0.618)$ & $(0.686)$ & $(0.610)$ & $(0.682)$ & $(0.631)$ & $(0.675)$ \\
\hline \multirow[t]{2}{*}{$R E T(k)$} & 0.467 & 0.339 & $0.703 * *$ & 0.267 & $0.604 * *$ & 0.495 & $0.534 *$ & 0.555 \\
\hline & $(0.537)$ & $(0.431)$ & $(0.325)$ & $(0.317)$ & $(0.270)$ & $(0.491)$ & $(0.320)$ & $(0.483)$ \\
\hline \multirow[t]{2}{*}{$\operatorname{RET}(k)(-1)$} & -0.011 & -0.016 & -0.152 & -0.079 & -0.082 & -0.086 & -0.208 & -0.114 \\
\hline & $(0.222)$ & $(0.256)$ & $(0.221)$ & $(0.268)$ & $(0.161)$ & $(0.267)$ & $(0.267)$ & $(0.275)$ \\
\hline \multirow[t]{2}{*}{$A T V$} & 0.004 & 0.004 & 0.005 & 0.005 & -0.004 & 0.004 & 0.002 & 0.004 \\
\hline & $(0.011)$ & $(0.011)$ & $(0.011)$ & $(0.011)$ & $(0.009)$ & $(0.011)$ & $(0.011)$ & $(0.011)$ \\
\hline \multirow[t]{2}{*}{ Volatility (-1) } & $0.458 * * *$ & $0.449 * * *$ & $0.462 * * *$ & $0.480 * * *$ & $0.375 * * *$ & $0.450 * * *$ & $0.460 * * *$ & $0.448 * * *$ \\
\hline & $(0.097)$ & $(0.099)$ & $(0.110)$ & $(0.087)$ & $(0.115)$ & $(0.100)$ & $(0.091)$ & $(0.100)$ \\
\hline \multirow[t]{2}{*}{ Volatility (-2) } & 0.078 & 0.099 & 0.077 & 0.055 & 0.099 & 0.095 & 0.050 & 0.095 \\
\hline & $(0.115)$ & $(0.124)$ & $(0.091)$ & $(0.124)$ & $(0.122)$ & $(0.116)$ & $(0.119)$ & $(0.114)$ \\
\hline \multirow[t]{2}{*}{ Volatility (-3) } & 0.126 & 0.119 & 0.130 & 0.143 & 0.181 & 0.119 & 0.167 & 0.119 \\
\hline & $(0.136)$ & $(0.143)$ & $(0.127)$ & $(0.140)$ & $(0.117)$ & $(0.137)$ & $(0.135)$ & $(0.135)$ \\
\hline Adjusted $\mathrm{R}^{2}$ & 0.343 & 0.337 & 0.374 & 0.336 & 0.385 & 0.344 & 0.354 & 0.348 \\
\hline$F$-statistic & 9.529 & 9.320 & 10.758 & 9.283 & 11.217 & 9.581 & 9.960 & 9.713 \\
\hline $\begin{array}{c}\text { Breusch-Godfrey LM } \\
\text { Test ( } p \text { value })\end{array}$ & 0.651 & 0.562 & 0.734 & 0.564 & 0.598 & 0.796 & 0.802 & 0.811 \\
\hline White & & & & & & & & \\
\hline $\begin{array}{c}\text { Heteroscedasticity } \\
\text { Test }(p \text { value })\end{array}$ & 0.326 & 0.470 & 0.441 & 0.459 & 0.077 & 0.417 & 0.446 & 0.447 \\
\hline
\end{tabular}

Note. Values enclosed in parentheses represent Newey-West HAC standard errors. $* * * p<0.01 ; * * p<0.05$ and $* p<0.1$.

Estimation of the regression model:

$V O L_{t}=\theta_{1}+\theta_{2} R E T(k)_{t}+\theta_{3} R E T(k)_{t-1}+\theta_{4} A T V_{t}+\theta_{5} V O L_{t-1}+\theta_{6} V O L_{t-2}+\theta_{7} V O L_{t-3}+u_{t}$

$V O L_{t}=\left|\hat{\sigma}_{m}\right|$.

$R E T(k)_{t}=$ proxy for testing the wealth effect, is the property price index return measured as an absolute value in percentage change, $k=A, B, C, D, E, A B C, D E, A L L$.

$A T V_{t}=$ absolute value of the $1^{\text {st }}$ order autoregressive residuals

Breusch-Godfrey LM Test at six lags of $V O L_{t}$. 
Table 5 Conditional Volatility - EGARCH Model

Regression results for various property market returns -- Whole Sample

Dependent Variable: $\log \left(h_{t}\right)$

1993:02 to 2001:07

\begin{tabular}{ccccccccc}
\hline \hline & $(k)=A$ & $(k)=B$ & $(k)=C$ & $(k)=D$ & $(k)=E$ & $(k)=A B C$ & $(k)=D E$ & $(k)=A L L$ \\
\hline$\Phi$ & $5.889^{* * *}$ & $5.956^{* * *}$ & $6.342^{* * *}$ & $4.648^{* * *}$ & $4.511^{* *}$ & $5.995^{* * *}$ & $4.910^{* * *}$ & $5.976^{* * *}$ \\
& $(1.252)$ & $(1.306)$ & $(1.080)$ & $(1.772)$ & $(2.343)$ & $(1.245)$ & $(1.638)$ & $(1.270)$ \\
$\alpha$ & -0.363 & -0.350 & $-0.432^{*}$ & -0.234 & -0.084 & -0.388 & -0.100 & -0.387 \\
& $(0.305)$ & $(0.293)$ & $(0.255)$ & $(0.256)$ & $(0.278)$ & $(0.301)$ & $(0.239)$ & $(0.296)$ \\
$\beta$ & -0.380 & -0.390 & $-0.486^{*}$ & -0.142 & -0.170 & -0.407 & -0.195 & -0.406 \\
& $(0.309)$ & $(0.323)$ & $(0.272)$ & $(0.413)$ & $(0.653)$ & $(0.312)$ & $(0.387)$ & $(0.316)$ \\
$\gamma$ & 0.024 & -0.002 & 0.017 & -0.028 & -0.116 & 0.030 & -0.093 & 0.029 \\
& $(0.143)$ & $(0.146)$ & $(0.134)$ & $(0.161)$ & $(0.133)$ & $(0.142)$ & $(0.152)$ & $(0.139)$ \\
$\phi_{1}$ & 0.142 & 0.041 & 0.218 & $0.309 *$ & $0.325 * * *$ & 0.159 & $0.353 * *$ & 0.178 \\
& $(0.235)$ & $(0.208)$ & $(0.161)$ & $(0.171)$ & $(0.099)$ & $(0.247)$ & $(0.144)$ & $(0.249)$ \\
$\phi_{2}$ & -0.002 & 0.056 & -0.054 & -0.224 & -0.085 & 0.007 & -0.320 & 0.001 \\
& $(0.176)$ & $(0.116)$ & $(0.193)$ & $(0.210)$ & $(0.245)$ & $(0.129)$ & $(0.199)$ & $(0.139)$ \\
$\phi_{3}$ & 0.009 & 0.010 & 0.009 & $0.012 *$ & 0.004 & 0.009 & 0.008 & 0.009 \\
Ljung-Box Q- & $(0.006)$ & $(0.006)$ & $(0.007)$ & $(0.006)$ & $(0.008)$ & $(0.006)$ & $(0.007)$ & $(0.006)$ \\
statistics (p value ): & & & & & & & & \\
Lag 1 & 0.506 & 0.528 & 0.520 & 0.512 & 0.747 & 0.487 & 0.755 & 0.482 \\
Lag 2 & 0.720 & 0.725 & 0.701 & 0.708 & 0.893 & 0.713 & 0.953 & 0.710 \\
Lag 3 & 0.393 & 0.450 & 0.376 & 0.581 & 0.481 & 0.399 & 0.811 & 0.397 \\
Lag 4 & 0.434 & 0.502 & 0.445 & 0.594 & 0.610 & 0.460 & 0.810 & 0.460 \\
Lag 5 & 0.568 & 0.633 & 0.579 & 0.730 & 0.742 & 0.598 & 0.894 & 0.599 \\
Lag 6 & 0.621 & 0.685 & 0.674 & 0.725 & 0.616 & 0.652 & 0.853 & 0.652 \\
\hline
\end{tabular}

Note. Values enclosed in parentheses represent Bollerslev-Wooldrige robust standard errors. *** $p<0.01 ; * * p<$

0.05 and $* p<0.1$.

Estimation of the EGARCH model:

$$
\log \left(h_{t}\right)=\bar{\Phi}+\alpha\left|\frac{\varepsilon_{t-1}}{\sqrt{h_{t-1}}}\right|+\beta \log \left(h_{t-1}\right)+\gamma \frac{\varepsilon_{t-1}}{\sqrt{h}_{t-1}}+\phi_{1} \operatorname{RET}(k)_{t}+\phi_{2} \operatorname{RET}(k)_{t-1}+\phi_{3} A T V_{t}
$$

$h_{t}=$ conditional variance in month $t$.

$R E T(k)_{t}=$ proxy for testing the wealth effect, is the property price index return measured as an absolute value in percentage change, $k=A, B, C, D, E, A B C, D E, A L L$.

$A T V_{t}=$ absolute value of the $1^{\text {st }}$ order autoregressive residuals. 
Table 6

Descriptive Statistics

\begin{tabular}{c|cccccccccc}
\hline \hline & VOL & RETA & RETB & RETC & RETD & RETE & RETABC & RETDE & RETALL & ATV \\
\hline Mean & 7.453 & 1.049 & 1.236 & 1.223 & 1.380 & 1.890 & 1.103 & 1.347 & 1.100 & 32.902 \\
Median & 6.785 & 0.788 & 0.923 & 0.934 & 0.992 & 1.397 & 0.829 & 0.969 & 0.814 & 30.428 \\
Maximum & 28.24 & 5.503 & 5.301 & 6.650 & 5.228 & 7.595 & 5.538 & 5.243 & 5.470 & 138.93 \\
Minimum & 2.840 & 0.000 & 0.043 & 0.045 & 0.000 & 0.043 & 0.037 & 0.000 & 0.000 & 0.283 \\
Std. Dev. & 3.775 & 0.938 & 1.019 & 1.126 & 1.181 & 1.624 & 0.966 & 1.169 & 0.963 & 27.391 \\
Skewness & 2.195 & 1.802 & 1.497 & 1.829 & 1.101 & 1.206 & 1.674 & 1.166 & 1.642 & 1.534 \\
Kurtosis & 11.134 & 7.855 & 5.331 & 7.492 & 3.685 & 4.154 & 6.851 & 3.832 & 6.651 & 6.222 \\
$\quad \begin{array}{c}\text { Sum } \\
\text { Sum Sq. Dev. }\end{array}$ & 760.21 & 107.00 & 126.0 & 124.73 & 140.77 & 192.73 & 112.55 & 137.37 & 112.19 & 3257.4 \\
Coefficient & 0.504 & 0.894 & 0.824 & 0.921 & 0.856 & 0.859 & 0.876 & 0.868 & 0.875 & 0.833 \\
of Variation & 88.816 & 104.90 & 128.02 & 140.92 & 266.32 & 94.299 & 137.91 & 93.585 & 73525 \\
Observations & 102 & 102 & 102 & 102 & 102 & 102 & 102 & 102 & 102 & 99 \\
\hline \hline
\end{tabular}

\begin{tabular}{c|ccccccccc}
\hline \hline & $r$ & $S D A$ & $S D B$ & $S D C$ & $S D D$ & $S D E$ & $S D A B C$ & $S D D E$ & $S D A L L$ \\
\hline Mean & 0.747 & 9.235 & 9.236 & 9.169 & 9.180 & 8.982 & 9.232 & 9.055 & 9.228 \\
Median & 0.578 & 8.928 & 8.916 & 9.006 & 8.652 & 7.957 & 8.905 & 8.374 & 8.872 \\
Maximum & 26.452 & 16.341 & 16.273 & 16.988 & 19.323 & 19.793 & 16.848 & 20.783 & 17.309 \\
Minimum & -34.823 & 5.974 & 5.527 & 5.304 & 5.105 & 5.144 & 5.891 & 4.426 & 5.769 \\
Std. Dev. & 9.247 & 2.035 & 1.914 & 2.169 & 2.595 & 2.955 & 2.068 & 2.637 & 2.097 \\
Skewness & -0.106 & 1.083 & 1.015 & 0.824 & 1.562 & 1.707 & 1.160 & 1.665 & 1.193 \\
Kurtosis & 4.772 & 4.560 & 4.643 & 3.828 & 6.347 & 5.853 & 4.881 & 7.186 & 5.059 \\
Sum & 76.149 & 914.28 & 914.31 & 907.70 & 908.81 & 889.25 & 913.93 & 896.40 & 913.59 \\
Sum Sq. Dev. & 8636.1 & 405.75 & 359.16 & 461.16 & 660.13 & 855.60 & 418.95 & 681.69 & 430.82 \\
Coefficient of & 12.379 & 0.220 & 0.207 & 0.237 & 0.283 & 0.329 & 0.224 & 0.291 & 0.227 \\
Variation & 102 & 99 & 99 & 99 & 99 & 99 & 99 & 99 & \\
Observations & 102 & & & & & & & &
\end{tabular}

$*$ All figures are expressed as percent per month (except for observations). 


\section{Figure 1 Monthly stock market volatility}
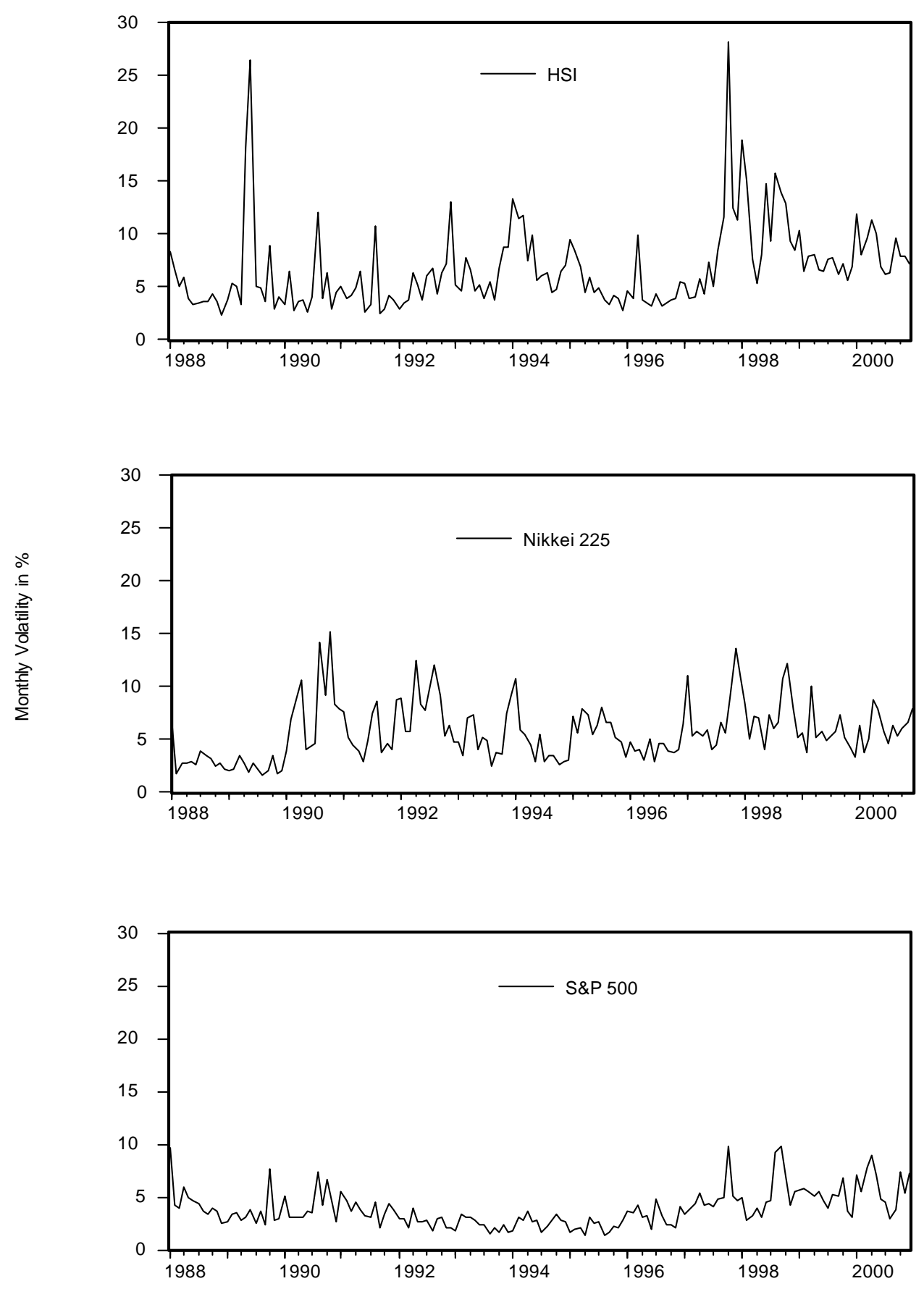